Arteterapia. Papeles de arteterapia y educación para inclusión social ISSN: $1886-6190$

http://dx.doi.org/10.5209/ARTE.54114

\title{
¡Aún no está acabada! Arteterapia en prisión
}

Kathya Adsuar ${ }^{1}$

Recibido: de marzo de 2016 / Aceptado: 13 de junio de 2016

Resumen. En este artículo, se dirige la mirada a una pequeña parte del trabajo del grupo de Arteterapia en el programa PID de la Presó Model de Barcelona.

En ocasiones, hay una producción que resulta especialmente significativa, que parece permitir el paso hacia un lugar diferente dentro del proceso global de la persona. Una producción que cambia el discurso, abre a nuevas emociones, que constituye en sí misma un proceso. ¿Qué ha ocurrido para llegar ahí? ¿Qué ha sido posible después?

¡Aún no está acabada!, una frase escuchada a menudo, tiene además la dimensión de referirse a un trabajo que perdura en la memoria, y parece tener así la capacidad de continuar.

Palabras clave: arteterapia, producción, proceso creativo, prisión.

Palabras clave: arteterapia; producción; proceso creativo; prisión.

\section{[en] It is not finished yet! Art therapy in prison}

\begin{abstract}
In this article, the focus goes to a small part of the group work in the art therapy program PID Model Presó of Barcelona.

Sometimes there is a production that is particularly significant, which seems to allow passage to a different place within the overall process of the person. A production that changes the speech, opens to new emotions, which is a process itself. What happened in order to get there? What has been possible afterwards?

It's not finished yet!: a phrase often heard, that has the added dimension of referring to a work that lingers in the memory, and therefore seems able to continue.

Keywords: art therapy; production; creative process; prison..
\end{abstract}

Sumario. 1. Introducción; 2. Encuadre; 3. El grupo de Arteterapia; 4. El uso de imágenes; 5. Las limitaciones del contexto; 6 . El parchís que no sirve; 7. Sobre la creación; 8 . El querubín que trae el silencio; 9. La mirada hacia la producción; 10. El corazón roto; 11. Conclusión; 12. Referencias bibliográficas.

Cómo citar: Adsuar, K. (2016) ¡Aún no está acabada! Arteterapia en prisión, en Arteterapia. Papeles de arteterapia y educación para inclusión social 11, 45-53.

1 Fundación Salud y Comunidad.

Terapeuta Ocupacional y Arteterapeuta. Experiencia en conductas adictivas y adultos mayores con y sin demencia. Investigadora en proyecto Arpa (Hospital del Mar, Barcelona)

E-mail: k.adsuar@gmail.com 


\section{Introducción}

El Arteterapia, como disciplina diferenciada de otras psicoterapias, tiene la particularidad, especialmente cuando se trabaja desde la plástica, de que la persona va generando a lo largo de su proceso, una serie de producciones o imágenes, a través del diálogo con el material artístico que utiliza. Las producciones son una forma de materializar lo que siente, quiere, puede o necesita expresar.

El elemento diferenciador del Arteterapia frente a otras disciplinas es que esta producción de imágenes deja una huella física, tangible, que puede volver a mirarse, por tanto, tiene la oportunidad de ser pensada de nuevo con esa distancia que proporciona el tiempo.

"El objeto me puede devolver una mirada no vista. ¿De qué manera la "devolución” del objeto - en tanto algo de lo exterior que retorna al sujeto- es capaz de transformarlo? Un efecto que se transforma en causa" (Reisin, 2006)

Esta cualidad de la producción como objeto a su vez conlleva una responsabilidad de la Arteterapeuta en el custodio y manejo de dichas producciones.

En la experiencia que compartiré, dirijo la mirada a producciones concretas de algunas de las personas que acompaño. Al igual que todos los pensamientos e ideas que se generan en un proceso psicoterapéutico únicamente verbal, no todas las producciones parecen tener el mismo peso o valor. De alguna manera, las primeras producciones pueden cumplir una función de entrada en el espacio simbólico de la terapia, un trabajo de vinculación con el lugar, los materiales y las personas. También podríamos decir que algunas hacen pensar en descansos y otras son especialmente significativas, que parecen constituir en sí mismas todo un proceso.

\section{Encuadre}

El programa PID es un programa psicoeducativo dirigido a personas con conductas adictivas que se lleva a cabo en la prisión de hombres Modelo de Barcelona desde hace más de 25 años. Se gestiona por la Fundación Salud y Comunidad y está subvencionado por el departamento de salud de la Generalitat de Cataluña.

El equipo de trabajo lo forman Francesca Spagnó, psicologa y coordinadora y Arcadi Minguet, educador social. Acoge también a alumnas de prácticas de los grados de psicología, educación social y máster en drogodependencias y colaboradoras como es mi caso.

Al PID se accede de manera voluntaria y en él se trabajan temas de salud, drogas, inclusión social y reflexión (un grupo abierto a la palabra). También realizan actividades extraordinarias en el centro como celebración de días mundiales, actividades conjuntas con teatro o la biblioteca, etc. Tiene dos grupos de trabajo, alta y baja intensidad, que exigen diferentes grados de implicación por parte de los participantes. El grupo de Arteterapia se lleva a cabo en el itinerario de alta intensidad, cuyas características importantes son el compromiso de abstinencia, convivencia en la misma celda y grupos de trabajo diarios. Los participantes se comprometen además a asistir a deporte y escuela. El grupo lo forman un máximo de 9 personas. 


\section{El grupo de Arteterapia}

El espacio de Arteterapia comienza en 2012. La implantación como un espacio consolidado dentro del programa ha sido difícil y compleja. En esta complejidad ha sido condicionante la inclusión en el equipo multidisciplinar, la propia Institución y el hecho de que el grupo es abierto; lo que significa que las personas que acuden van cambiando, asistiendo de media durante unos 4 o 5 meses cuando completan el programa. Esto no siempre es así porque el programa no se ajusta a su demanda, no consiguen vincularse al mismo o aspectos ajenos a este relacionados con la Institución (sanciones, conducciones...)

El grupo tiene una frecuencia semanal y una duración de 90 minutos. La sala es cerrada y sin cámaras, lo que garantiza un ambiente confidencial y protegido.

Trabajamos con material plástico no muy abundante; pintura, barro, plastilina, ceras, lápices de colores, rotuladores... y material reciclado: revistas, cartones, telas...

Al tratarse de un grupo abierto, cada cierto tiempo hay personas que se incorporan y personas que marchan. Cuando una persona comienza, invito al resto a explicar algo acerca de su experiencia en el grupo, qué hacemos aquí. Este es un momento bastante interesante porque me ayuda a ver mejor en qué momento está cada uno y cómo entienden el espacio. Si es necesario, por supuesto, aclaro los aspectos que no se hayan explicado.

En el primer día de cada persona, le propongo pensar en un objeto con el que se sienta identificado y representarlo con el material. Cuando alguien se despide, le animo a mirar el trabajo hecho y a despedirse a través de una producción que sirva de cierre.

Dejando a un lado estos dos momentos de inicio y cierre, trabajamos sin consigna. Cada persona hace lo que quiere con el material que elige.

A lo largo de estos tres años, ha habido producciones que han tomado más peso que las otras. Echando la mirada atrás aprecio que casi siempre han sido trabajo de varias sesiones y que después, de diferentes maneras, perduran en la memoria.

\section{El uso de imágenes}

Me gustaría explicar la forma en que llego al tema de este artículo. En el momento en que me planteo una reflexión en torno al espacio de Arteterapia, me encuentro trabajando con un grupo pequeño, en el cual hay un participante con ciertos rasgos paranoicos. Cada cierto tiempo, planteo la posibilidad de hacer fotos de las producciones, explicando que el fin de las mismas es, por un lado, mi propio registro de los procesos, y por otro, la posibilidad de compartir en contextos profesionales el trabajo del grupo. Esta persona, muy vinculada al espacio y conmigo, se muestra muy dispuesta a lo que propongo y me da su autorización verbal.

Por normas de la Institución, la entrada de cámaras está totalmente prohibida. La manera en que registro las producciones es sacando la caja hasta el despacho, y devolviéndola después.

El día que aparezco en la galería con la caja de este participante, él no recuerda haberme dado este permiso y noto cierta paranoia en su actitud. En mi respuesta, le recuerdo nuestra charla, pero le digo que sí ha cambiado de opinión por supuesto 
puedo borrar las fotos. Me dice que no hay problema, que simplemente no se acordaba y posteriormente me firma la autorización escrita.

Esta escena me hace pensar que quizá no es una buena idea mostrar ninguna imagen de sus producciones. Me parece un posicionamiento ético guardarme de mostrar el trabajo de una persona que duda en querer hacerlo. Siento que su permiso puede ser una muestra de agradecimiento hacia mí, y en este sentido quizá sea una clase de abuso servirme de ello para generar una reflexión. (GuggenbhülCraig, 1974). Pienso que tal vez es posible su autorización, y a la vez tiempo después convertirse en un alentador de su paranoia.

Esto me lleva a pensar en cómo poder hablar del grupo sin mostrar ninguna imagen. Si es posible hablar del trabajo en Arteterapia sin ninguna fotografía que apoye las palabras. Me parece interesante también dar la oportunidad a quien lea de formar su propia imagen a partir de la emoción que ha suscitado la creación de esa producción. Esto puede ser también un ejercicio de acercamiento a ese colectivo con el que trabajo, una invitación a la empatía con las personas privadas de libertad. (Winnicott, 1990)

\section{Las limitaciones del contexto}

El contexto en que trabajamos, una prisión, es absolutamente rígido y normativo. Cómo puede influir esto al grupo de arteterapia es uno de los aspectos que más me ha costado asimilar para poder construir un setting seguro. (Peinado, 2012). Con respecto a las producciones, nos afecta por varios motivos. Por un lado, hay materiales que no está permitido tener en una celda, por lo que al acabar el programa no pueden llevar consigo. Con el tiempo, para minimizar este impacto, he ido eliminando estos materiales de nuestro espacio.

Por otro lado, a veces, por una sanción de la institución, algunas personas cambian de galería y salen automáticamente del programa. En este caso puedo buscarles y preguntar qué quieren hacer con sus trabajos, pero esta conversación tiene lugar fuera de nuestra sala, en un bunker central, con muchos ojos mirando. Obviamente las producciones no están presentes en este diálogo; precisamente por esos ojos ajenos no parece un lugar adecuado para mirar las imágenes producidas.

Ha ocurrido a veces también que la persona marchará por conducción (traslado a otra prisión); esta situación no puede comunicarse a la persona por protocolo de riesgo de fuga, siendo en este caso imposible nombrar un final.

Todas estas limitaciones hacen que a menudo me encuentre con producciones con las que no sé qué hacer. Integrar esto como parte inevitable del contexto ha supuesto todo un trabajo personal que he tenido que ir asimilando. En un principio recogía los trabajos y los guardaba en el despacho. El equipo en seguida se dio cuenta de esta dificultad y hablamos sobre ella y sobre el hecho de que esto ocurre continuamente, era necesario buscar otra solución. Entonces empecé a "esconder" las producciones. Me decía a mí misma que las tiraría. Cuando estuviera preparada. Lo iba haciendo poco a poco, como podía.

Hoy, aunque me provoca la misma sensación en el estómago que intento controlar, retiro las producciones del espacio, las documento y tiro. 
Haré pues un recorrido por el proceso de creación, reflexionando sobre si un trabajo es posible cuando existe la posibilidad de separarse de él de una manera digamos traumática.

\section{El parchís que no sirve}

A comienza en el espacio de Arteterapia en un momento en que el grupo es vivido con gran rechazo. No entienden para qué sirve en un programa de drogas, no saben qué hacer. No se encuentran cómodos ni tan siquiera para decirme, y expresan este malestar en otros grupos. A se presenta pintando su caja con los colores de su equipo, y tras varias semanas en que falta por bajas médicas que finge, hacemos una sesión donde hablamos de las dificultades, expectativas y demandas. Una de sus peticiones es traer juegos de mesa. Mi propuesta es inventar juegos nosotros, y así lo hacen. Recuerdo cómo A comparte al final que esto no es Arteterapia.

Tras esta sesión, continúa pintando su caja durante varios días, pero parece perdido. En ocasiones siento que el grupo parece reírse de él, de una manera velada. Le propongo entonces pintar su caja por la parte interior, aquella que no tiene porqué mostrar. Parece entonces empezar de nuevo en el grupo, su producción me hace pensar en otra presentación. Aparece una imagen diferente; la bandera de su país; con un discurso y materiales diferentes.

En el siguiente encuentro comienza un parchís. Sobre una base de cartón, dibuja el tablero. Desde el primer momento se muestra dudoso en el número de casillas, en su tamaño correcto, agobiado por la necesidad de hacerlo bien. Le devuelvo en varias ocasiones que puede ser un parchís diferente, que puede construirlo como quiera.

La semana posterior dice traer el parchís "en la cabeza", comienza con la misma decisión y energía que poco a poco van desapareciendo en sus dudas. Continuamente hace y borra. (Bonilla Rius, 2006) Ocurre que la pequeña goma de borrar se acaba y este agobio general tiene un pico de intensidad. Yo sigo insistiendo en la posibilidad de hacer un parchís diferente. Pero $A$ quiere borrar y encuentra la forma. Con pintura blanca borra prácticamente todas las casillas y una y otra vez empieza de nuevo.

En su tercera sesión con el parchís, vuelve decidido y el proceso se repite. Con tanta pintura, el cartón empieza a deshacerse. Entonces dice:

- ¡Ya está bien, estoy harto, lo voy a tirar!

El grupo le dice que debería valorar más su trabajo. Le remito a la impulsividad de la decisión, invitándolo a tomar un tiempo para pensarlo. Insiste en que está harto y quiere tirarlo. Tras dejarlo en el cubo de basura, coge una imagen de una revista en que aparece un bebé y dice que se parece a él, que no sabe hacer las cosas. Comparte también cómo se siente cuando tiene paranoias y el periódico parece dirigirse a él; es la primera vez que puede hablar de esto en el espacio.

Tras el parchís, $A$ trabaja en otras producciones, barro, revistas... Una de ellas es un pollito de lana, que también le reporta diversas dificultades. Sin embargo, observo un gran cambio en la manera de posicionarse frente a esos obstáculos, ya no se enfada, no se agobia. Simplemente dice que no le sale, y lo vuelve a intentar.

En todas las ocasiones en que $A$ presenta el espacio a nuevas personas que se incorporan, nombra el parchís. 
- ¡Yo hice un parchís! Pero no me salía así que al final lo tiré.

Este trabajo de $A$, cuando lo observo desde la distancia, me hace pensar en mi insistencia en que el parchís podía ser diferente, pensando que el trabajo estaba ahí. Sin embargo, su proceso caminaba por otro lugar. Quizá permitirse volver atrás, empezar de nuevo, poder decir basta cuando ya no puedo. Algo del rendirse y que eso también sea posible.

\section{Sobre la creación}

El concepto de creación es complejo (Freud, 1913). Como con cualquier otro, parece que una logra entenderlo mejor cuando encuentra sus propias palabras. De alguna manera, la entiendo en contraposición a la mera expresión. Nos expresamos cada día, a través de múltiples lenguajes que dominamos en mayor o menor medida. Una metáfora podría ser a la idea de un puzzle. La expresión sería sacar todas las piezas sobre la mesa y hacer algo con ellas; mirarlas, tocarlas... En algún momento, dos de ellas se encuentran y el puzzle empieza a tomar forma, la creación aparece en escena.

Estas producciones de las que hablo, me hacen pensar en esas piezas que encajan, aunque solo sean dos de un puzzle enorme. Algo toma sentido, y sobre todo, algo cambia.

\section{El querubín que trae el silencio}

$L$ es un chico latino, tiene dos hijos pequeños que están con la madre, de la que se está separando. Durante las 7 primeras sesiones, va probando materiales, sobre todo recorta imágenes y toca algo de plastilina. En todas sus producciones, rodea las imágenes de una gran cantidad de texto donde las explica y habla principalmente de sus hijos. Cuando comparte el trabajo, repite un discurso que suena aprendido, y más o menos reproduce lo que ha escrito en sus textos.

Después ocurren tres sesiones como de tránsito. En la primera de ellas, dice que no quiere hacer nada, me pide poner música pero tiene un problema con el enchufe, así que pasa toda la sesión intentando arreglarlo. En las dos siguientes comienza a dibujar, la cantidad de texto empieza a disminuir, si bien sigue presente un discurso muy similar cuando compartimos el trabajo.

En el encuentro posterior escoge una imagen de un querubín y decide copiarla. Desde el momento en que comienza, aparece el silencio. (Del Rio, 2006). Trabaja concentradísimo, sin despegar la mirada del papel que dibuja y la imagen que copia. Esta producción le lleva un mes de trabajo, en el cual consigue realizar una reproducción muy fiel del querubín. Primero dibuja el cuerpo, y después añade todos los detalles de alrededor. En una ocasión, levanta la mirada y ve que estoy observando. Sonríe y dice:

- ¡Me está saliendo!

Al final de todas estas sesiones, en el momento de compartir sólo dice "aún no está acabada"

Cuando por fin termina comenta que no le ha salido del todo bien, parece que le cuesta reconocerse el mérito. Le devuelvo lo que he podido observar de la manera 
en que trabaja; la seguridad y concentración con que dibuja y que apenas utiliza el borrador, me transmite mucha seguridad en lo que hace.

$L$ continúa en el grupo haciendo copias de otras imágenes, donde empieza a permitirse añadir detalles propios. En cierta ocasión comparte que está a punto de ser padre de nuevo, con otra mujer que está en su país. Nos cuenta cómo se siente al no poder estar ahí en esos momentos tan importantes.

Unas sesiones después, me pregunta cómo he hecho la foto del querubín, si he puesto el original encima. Le contesto que es una cuestión interesante, que seguramente yo no he hecho la foto como la habría hecho él. Me dice que él haría dos fotos separadas, porque si tuviera que exponerlo en un museo estaría su cuadro en grande, y a un lado, en pequeño, la imagen que copió.

En estos cambios, se hace evidente su proceso. Al igual que otros muchos participantes del programa, parece tener dificultad para elaborar sus emociones, le cuesta reconocerlas. Sin embargo, hay todo un cambio en su manera de estar en Arteterapia, en cómo utiliza el tiempo que tenemos. Con el querubín, el discurso repetido desaparece, y surgen emociones nuevas, que poco a poco puede compartir (Winnicott, 2000).

\section{La mirada hacia la producción}

En mi experiencia en la prisión, puedo observar diferentes grados de vinculación de los participantes con su producción. Algunas personas tienen facilidad para instalarse en un discurso aprendido y les cuesta mucho, sin embargo, poner palabras a lo que han hecho, o relacionarlo con algo de cómo se sienten. A veces les resulta difícil mirar su trabajo, o aparece la presión estética y sólo pueden fijarse en el resultado.

Por otro lado, siento que el dirigir la mirada hacia la producción resulta un salvoconducto de gran potencialidad. A veces, se plantea a una situación delicada, en que el dolor aflora; la persona comparte vivencias dolorosas a las que es muy difícil responder, una no sabe qué decir en determinados momentos. Me doy cuenta cada vez más, de que dirigir la mirada al trabajo puede ser de gran ayuda. Algunas producciones tienen la capacidad de sostenernos a ambos, a veces es ahí donde se puede encontrar alguna respuesta.

\section{El corazón roto}

$D$ es un chico muy joven que entra al programa en una situación de gran fragilidad emocional. Se presenta con una producción en barro que evoca un tenedor que talló años atrás y rememora como "su mejor obra", le costó mucho terminarlo. Después, durante varias sesiones pinta con témperas una escena de Pirineos, que relaciona con la libertad y una bonita etapa de su vida.

Cuando lleva unas pocas sesiones, al grupo sólo acuden su compañero de celda y él, comentan sobre antiguos compañeros, cosas que les han robado... Escuchando todo esto, nombro la palabra pérdidas y les propongo trabajar en esa idea. Entonces $D$ se queda blanco y me dice que prefiere seguir con su dibujo. 
Dentro de mí salta un resorte, y siento miedo a haber hecho una propuesta insostenible para él.

Al coger su pintura, se acerca a mí y me dice que está impactado porque él ha perdido a gente. Le contesto que está bien continuar con su dibujo.

A la pintura de Pirineos, añade algunos animales y un refugio de montaña. Entonces me dice que intentará lo que les he sugerido. Tras su reacción inicial, intento ser cuidadosa y le insisto en que no tiene porqué hacerlo. Dice que sí, y me pregunta qué hace con la pintura. Se me ocurre que puede sostenerle y le propongo colocarlo "de fondo" mientras trabaja.

Con barro, realiza un corazón al que le hace una incisión, un corazón roto.

En el momento de compartir, la tristeza en el ambiente es infinita. $D$ expresa que le gustaría gritar, y de nuevo siento miedo, de que no pueda controlarse, de que pueda hacerse daño, de no poder cerrar ese corazón antes de irnos.

Casi siempre, si sabemos mirar, las personas nos dan pistas. $D$ comenta que estaría bien gritar, pero desde esa cumbre que ha dibujado en su montaña. Es él quien me remite a la producción y siento que ahí podemos sostenernos. Su compañero dice que hay que enfrentarse al dolor, contesto que en algunos momentos es así, también podemos refugiarnos en el espacio. Como ese refugio que ha dibujado, el grupo puede ser un descanso en un espacio hostil, duro.

Es evidente que ese corazón que ha modelado es importante y necesita protección, de manera que les propongo envolverlo con cuidado entre muchos papeles. Así hacemos entre los tres, y lo guarda en su caja.

En esta sesión, el cierre es posible a través de estas dos intervenciones, directamente relacionadas con sus producciones, mirar a una para sostenernos, proteger la otra para poder volver.

En la siguiente sesión, alguien se incorpora y $D$ expone qué hacemos en Arteterapia de una manera clarísima y completa, nombrando todo lo importante. Después, saca su corazón, lo pinta de rojo y sin decir nada sobre él lo vuelve a guardar.

A partir de entonces, va realizando producciones diversas que generalmente trabaja durante varios días. A través de ellas, puede hablar de sus inquietudes personales, de su vida en el centro penitenciario, de sus expectativas. Su vinculación con el espacio es clara, parece sentirse protegido. Me parece que haber envuelto ese corazón le ha permitido sentirse seguro en este espacio.

Diez sesiones después de la producción del corazón, puede compartir por primera vez experiencias concretas de su vida, relacionadas con el consumo de drogas y con sus vivencias familiares. Nos cuenta recuerdos y pensamientos muy duros, muy dolorosos. Me llama mucho la atención la manera tan distinta en que es capaz de hacerlo esta vez, pues ya no le siento tan frágil, tan roto.

Siento que en el proceso de $D$ quizá fue determinante poder mostrar su corazón roto. Lo que en un principio parecía insostenible para ambos, fue una experiencia de acogida y sostén, abriendo la posibilidad a todo el trabajo posterior.

\section{Conclusión}

Todo esto me lleva a pensar, desde otro lugar, en la importancia del destino físico final del trabajo. (Winnicott, 1959) No quiero decir con esto que la producción 
como objeto de la que hablaba antes no resulte importante. En el contexto penitenciario además, estas imágenes que van construyendo pueden ser una de sus pocas posesiones en este lugar de gran precariedad. Sería deseable poder conservarlas siempre que la persona lo decida, pero la realidad es que esto no siempre es así. Por supuesto que la producción en sí puede ser muy importante; aquí me refiero a una mirada más amplia, esta huella que tiene la capacidad de dejar puede ir más allá de su destino físico.

En la prisión, hacemos una intervención corta con muchas limitaciones, aun así es posible observar los procesos personales de los participantes, y la capacidad que tiene el espacio, y algunas producciones especialmente, de perdurar en la persona que la ha creado.

Puedo identificar estas producciones de las que he hablado como un proceso en sí mismas, a las que dan un valor muy claro. Parece como si en este hacer el trabajo se acelerase, la persona de repente está sumergida en aspectos importantes que determinan su manera de posicionarse después, bien en el espacio o bien conmigo.

¡Aún no está acabada! Independientemente de que acabe en la basura, la imagen tiene la capacidad de permanecer viva, y de alguna manera así continuar trabajando, dejar abierta la posibilidad a nuevos caminos, nuevos pequeños cambios.

\section{Referencias bibliográficas}

Bonilla Rius, A (2006) El acto de borrar. Revista de Arteterapia: Papeles de Arteterapia y educación artística para la inclusión social. $\left(n^{\circ} 1\right)$ 75-77

Freud, Sigmund, (1913) Múltiple interés del psicoanálisis. Capítulo II. El interés del psicoanálisis para la estética (recurso electrónico). Ob. C V II .Biblioteca Nueva. Madrid. Obtenido el 28 de mayo del 2016, de http://www.uruguaypiensa.org.uy/andocasociado.aspx?166,685

Guggenbhül-Craig, A. (1974): Poder y destructividad en psicoterapia. Caracas, Monte Ávila editores.

Peinado, A (2012) Desde la sombra .El setting de arteterapia en el contexto penitenciario. Revista de Arteterapia: Inspira ( $\left.{ }^{\circ} 1\right)$ 31-42

Reisin, A (2006) Semánticas y morfologías. Nuevos territorios a partir del Arteterapia. Revista Campo Grupal, $\mathrm{n}^{\mathrm{o}}$ 80. Citado en recurso electrónico: http://www.simbolica.org/la-funcion-de-la-produccion-en-el-espacio-de-arteterapia/

Del Rio, M (2006) Formas para el silencio. Revista de Arteterapia: Papeles de Arteterapia y educación artística para la inclusión social. $\left(n^{\circ} 1\right)$ 69-74

Winnicott, D. (1959) El destino del objeto transicional. Trabajo preliminar para una charla pronunciada en la Asociación de Psicología y Psiquiatría Infantil, de Glasgow, el 5 de diciembre de 1959.

https://docs.google.com/document/d/1OwNkAriIwYQImOBNkviXRtKDIn4qrcIILDJWrg3 487Q/edit

Winnicott, D. (1990) Deprivación y delincuencia. (Recurso electrónico). Argentina: Paidos, Psicología profunda. Obtenido el 21 de mayo del 2014, de http://es.scribd.com/

Winnicott, D. (2000). Realidad y juego. Capítulo 5 La creatividad y sus orígenes. Barcelona: Gedisa Editorial. 